\title{
Preparation and Characterization of Some Bivalent Metal Complexes of Benzimidazole Derivatives
}

\author{
IRSHAD ALI \\ Department of Chemistry, B.N. College, Patna University, Patna, India \\ dralibnc@gmail.com
}

Received 2 October 2015 / Accepted 9 October 2015

\begin{abstract}
The complexes of iron(II) and cobalt(II) with $N$-benzyl-2-(2'-pyridyl)-6-methyl benzimidazole (Bnpymbz) and $N$-butyl-2-(2'-pyridyl)-6-methyl benzimidazole (Btpymbz) of composition $\left[\mathrm{FeL}_{2}(\mathrm{NCS})_{2}\right],(\mathrm{L}=$ Bnpymbz or $B t p y m b z)$ and $\left[\mathrm{CoL}_{2}(\mathrm{NCS})_{2}\right],(\mathrm{L}=$ Bnpymbz or Btpymbz) and $\left[\mathrm{ML}_{2}\left(\mathrm{H}_{2} \mathrm{O}\right)_{2}\right] \mathrm{SO}_{4},\left(\mathrm{M}=\mathrm{Co}^{\mathrm{II}}\right.$ or $\mathrm{Fe}^{\mathrm{II}}$ and $\mathrm{L}=$ Bnpymbz or Btpymbz $)$ have been synthesised in aqueous ethanolic medium and analysed to ascertain their composition. The magnetic susceptibility, electronic absorption studies and infrared spectra of ligands and their complexes have been determined to propose their structure. The electrical conductance measurement of complexes were determined to find out the ionic nature of complex molecule. The magnetic moment of complexes occur in the range of spin free octahedral structure $\mathrm{Fe}(\mathrm{III})$ complexes, 4.89-4.92 B.M, Co(II) complexes, 5.02-5.12 B.M. The infrared spectra of complexes showed N-bonded thiocynate group ( $\mathrm{vCN}=2070-2092 \mathrm{~cm}^{-1}$ broad strong). The diaqua complexes $\left[\mathrm{ML}_{2}\left(\mathrm{H}_{2} \mathrm{O}\right)_{2}\right] \mathrm{SO}_{4},\left(\mathrm{M}=\mathrm{Co}^{\mathrm{II}}\right.$ or $\left.\mathrm{Fe}^{\mathrm{II}}\right)$ display characteristic i.r band $\left(v_{3}=1105-1112 \mathrm{~cm}^{-1}\right.$ strong, broad) of ionic sulphate group. The electronic absorption band structures were consistent with approximately octahedral geometry.
\end{abstract}

Keywords : Iron(II), Cobalt(II), Benzimidazole, 2-(2'-Pyridyl) derivatives

\section{Introduction}

Among various type of coordinating ligand the coordination complexes of benzimidazole derivatives have received significant upsurge of interest during past few years due to active therapeutic imidazole nuclei present in benzimidazole derivatives and their ability to form strong bond with metal atom leading to their wide application in pharmacophore, industrial polymer, nanoparticle and supramolecules ${ }^{1-6}$. The benzimidazole nucleus and its derivatives are known to play active and crucial role in the structure and functioning of some biologically important molecule, particularly in vitamin $\mathrm{B}_{12}$ and Heam system ${ }^{2}$.

\section{Experimental}

The ligands were prepared in two steps by condensing $o$-phenylenediamine derivative with $\alpha$-picolinic acid. The product formed was then treated with benzyl chloride or $n$-butyliodide in tetrahydrofuran in presence of $\mathrm{K}_{2} \mathrm{CO}_{3}$. 


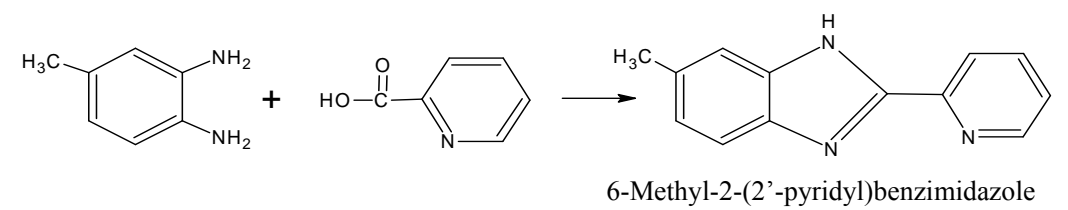<smiles>Cc1ccc2nc(-c3ccccn3)[nH]c2c1</smiles>

$N$-Benzyl-2-(2'-pyridyl)-6-methylbenzimidazole

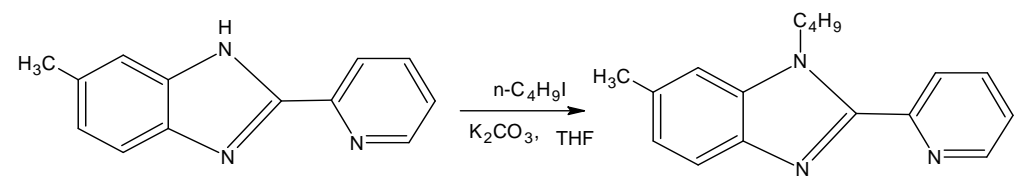

\section{Step-I}

$N$-Butyl-2-(2'-pyridyl)-6-methylbenzimidazole

$12 \mathrm{~g}(0.1 \mathrm{~mol})$ of 4-methyl-1,2-diaminobenzene was mixed thoroughly with $12.3 \mathrm{~g}(0.1 \mathrm{~mol})$ of $\alpha$-picolinic acid and taken in $25 \mathrm{~mL}$ polyphosphoric acid and heated gently in oil bath at $100{ }^{\circ} \mathrm{C}$ and then temperature was raised to $160-165^{\circ} \mathrm{C}$ and heated for three hours more. The blue melt formed was cooled and dissolved in hot water. The aqueous solution was neutralised with $\mathrm{NaOH}$ solution when light pink precipitate was formed. The pink precipitate was dissolved in dilute $\mathrm{HCl}$ and heated by adding active charcoal to remove coloured impurity. The solution was filtered and neutralised with dilute $\mathrm{NaOH}$ slowly $(\mathrm{pH}$ 6-7) when cream yellow product was separated. The product was recrystallised with hot ethanol to give pure product, M.P. $206-207{ }^{\circ} \mathrm{C}$, Nitrogen found $25.5 \%$, Calculated for $\mathrm{C}_{13} \mathrm{H}_{11} \mathrm{~N}_{3}$ is $25.56 \%$.

\section{Step-II}

The benzyl and $n$-butyl derivatives of 6-methyl-2-(2'-pyridyl)benzimidazole (Pymbz) was prepared by condensing Pymbz with benzyl chloride or $n$-butyliodide in tetrahydrofuran in presence of finely powdered potassium carbonate at $60-70{ }^{\circ} \mathrm{C}$.

\section{Procedure}

Stoichiometric proportion of Pymbz (0.05 mol) was dissolved in $40 \mathrm{~mL}$ tetrahydrofuran and treated with $(0.06 \mathrm{~mol})$ of benzyl chloride or $n$-butyliodide. The mixed solution was treated with $0.5 \mathrm{~g} \mathrm{~K}_{2} \mathrm{CO}_{3}$ and refluxed at $60-70{ }^{0} \mathrm{C}$ for three hours. The refluxed solution was filtered and concentrated to half volume and cooled when cream white crystalline precipitate separated. The products were recrystallised with ethanol. The dried product was analysed, M.P. found for $N$-benzyl derivative $192-193{ }^{\circ} \mathrm{C}$. Nitrogen found, $13.97 \%$, required for $\mathrm{C}_{20} \mathrm{H}_{17} \mathrm{~N}_{3}$, Nitrogen-13.98\%. M.P. for $n$-butyl derivative $187-188^{\circ} \mathrm{C}$. Nitrogen found $15.6 \%$, required for $\mathrm{C}_{17} \mathrm{H}_{9} \mathrm{~N}_{2}, \mathrm{~N}=15.8 \%$.

Preparation of complexes: $\left[\mathrm{ML}_{2}\left(\mathrm{H}_{2} \mathrm{O}\right)_{2}\right] \mathrm{SO}_{4}\left(\mathrm{M}=\mathrm{Co}^{\mathrm{II}}\right.$ or $\mathrm{Fe}^{\mathrm{II}}$ and $\mathrm{L}=$ Bnpymbz or Btpymbz)

About 10 millimole of metal sulphate was dissolved in $30 \mathrm{~mL}$ aqueous ethanol and treated with 20 millimole of ligand dissolved in hot ethanol. The resulting mixture was concentrated when coloured complexes separated gradually. The complexes were collected on a Buckner funnel and dried in a desiccators over $\mathrm{CaCl}_{2}$ 
Preparation of complexes: $\left[\mathrm{ML}_{2}(\mathrm{NCS})_{2}\right]\left(M=\mathrm{Co}^{I I}\right.$ or $\mathrm{Fe}^{I I}$ and $L=$ Bnpymbz or Btpymbz)

About 10 millimole of metal chloride was dissolved in $40 \mathrm{~mL}$ aqueous ethanol and treated with 20 millimole of appropriate ligand and mixed $2 \mathrm{~g} \mathrm{KCNS}$. The resulting solution was refluxed for one hour when dithiocyanato complexes separated. The complexes were collected on a Buckner funnel and dried over $\mathrm{CaCl}_{2}$. The analytical results and physical data of complexes are shown in Table 1.

\section{Results and Discussion}

The results of analytical analysis of complexes of $N$-butyl-2-(2'-pyridyl)-6-methyl benzimidazole (Btpymbz) and $\mathrm{N}$-benzyl-2-(2'-pyridyl)-6-methyl benzimidazole (Bnpymbz) with iron (II) and cobalt (II) correspond to compositions $\left[\mathrm{ML}_{2}(\mathrm{NCS})_{2}\right],\left(\mathrm{M}=\mathrm{Co}^{\mathrm{II}}\right.$ or $\mathrm{Fe}^{\mathrm{II}}$ and $\mathrm{L}=$ Btpymbz or Bnpymbz $)$ and $\left[\mathrm{ML}_{2}\left(\mathrm{H}_{2} \mathrm{O}\right)_{2}\right] \mathrm{SO}_{4}, \quad\left(\mathrm{M}=\mathrm{Co}^{\mathrm{II}}\right.$ or $\mathrm{Fe}^{\mathrm{II}}$ and $\mathrm{L}=$ Btpymbz or Bnpymbz). The complexes are stable in air and dissolve in ethanol. The DMF solution of complexes $\left[\mathrm{ML}_{2}(\mathrm{NCS})_{2}\right.$ display negligible electrical conductance value indicating non ionic nature of thiocyanato complexes. The complexes $\left[\mathrm{ML}_{2}\left(\mathrm{H}_{2} \mathrm{O}\right)_{2}\right] \mathrm{SO}_{4}$ dissolve in DMF and their solutions at room temperature display electrical conductance value in the range 152$156 \mathrm{~mol}^{-1} \mathrm{ohm}^{-1} \mathrm{~cm}^{2}$, supporting the ionic nature of sulphate ${ }^{8}$. The magnetic moment of iron (II) complexes at room temperature was found to be 4.82- $4.92 \mathrm{BM}$ and those of cobalt (II) complexes $\left[\mathrm{CoL}_{2}(\mathrm{NCS})_{2}\right]$ and $\left[\mathrm{CoL}_{2}\left(\mathrm{H}_{2} \mathrm{O}\right)_{2}\right] \mathrm{SO}_{4}$ were found to be 5.02 and $4.86 \mathrm{BM}$ respectively. The electronic absorption spectra of iron (II) complexes display a medium band at $490 \mathrm{~nm}\left[\mathrm{FeL}_{2}(\mathrm{NCS})_{2}\right]$ and at $510 \mathrm{~nm}$ for $\left[\mathrm{FeL}_{2}\left(\mathrm{H}_{2} \mathrm{O}\right)_{2}\right] \mathrm{SO}_{4}$ assignable to ${ }^{5} \mathrm{~T}_{2 \mathrm{~g}} \rightarrow{ }^{5} \mathrm{E}_{\mathrm{g}}$ transitions in octahedral field ${ }^{7}$. The cobalt(II) complexes shows two weak ligand field transitions near $430 \mathrm{~nm}$ and 520-530nm attributed to ${ }^{4} \mathrm{~T}_{1 \mathrm{~g}} \rightarrow{ }^{4} \mathrm{~T}_{1 \mathrm{~g}}(\mathrm{P})$ and ${ }^{4} \mathrm{~T}_{1 \mathrm{~g}} \rightarrow{ }^{4} \mathrm{~A}_{2 \mathrm{~g}}$ transitions respectively in octahedral field ${ }^{7}$. The infrared spectrum of ligand shows $v(\mathrm{CN})$ of benzimidazole ring at 1632 and $v(\mathrm{C}=\mathrm{N})$ pyridine ring at $1595 \mathrm{~cm}^{-1}$. The complexes of iron (II) and Co (II) shows $v(\mathrm{C}=\mathrm{N})$ vibration at lower frequency located at $1610 \mathrm{~cm}^{-1}$ indicating involvement of $(\mathrm{C}=\mathrm{N})$ nitrogen in bond formation ${ }^{9}$. The complex sulphate $\left[\mathrm{FeL}_{2}\left(\mathrm{H}_{2} \mathrm{O}\right)_{2}\right] \mathrm{SO}_{4}$ shows $v_{3}\left(\mathrm{SO}_{4}\right)$ vibration at $1108 \mathrm{~cm}^{-1}$ as broad and strong band and $v_{4}$ at $615 \mathrm{~cm}^{-1}$ as weak band suggesting ionic nature of sulphate ${ }^{8}$. The thiocyanato complex $\left[\mathrm{CoL}_{2}(\mathrm{NCS})_{2}\right],(\mathrm{L}=$ Btpymbz or Bnpymbz) shows $v(\mathrm{C}=\mathrm{N})$ vibration at $2085-2090 \mathrm{~cm}^{-1}$ supporting N-bonding of NCS in complexes. Thus from physical data and elemental analysis, six coordinated octahedral structures are suggested for both $\mathrm{Fe}(\mathrm{II})$ and $\mathrm{Co}(\mathrm{II})$ complexes. The probable structures of complexes are shown in Figure $1 \& 2$.

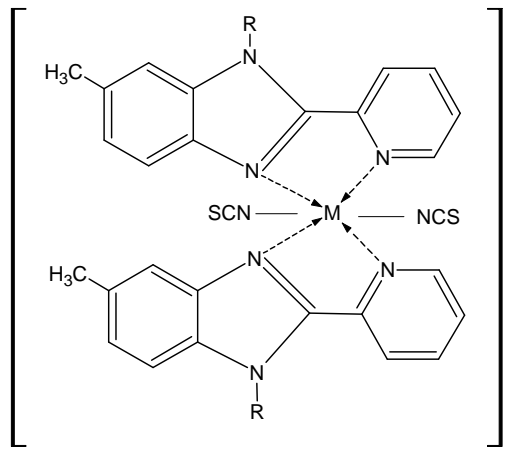

Figure 1. Structure of $\left[\mathrm{ML}_{2}(\mathrm{NCS})_{2}\right]$ $\left(\mathrm{M}=\mathrm{Fe}^{2+}\right.$ or $\mathrm{Co}^{2+}, \mathrm{R}=n$-Butyl or benzyl)

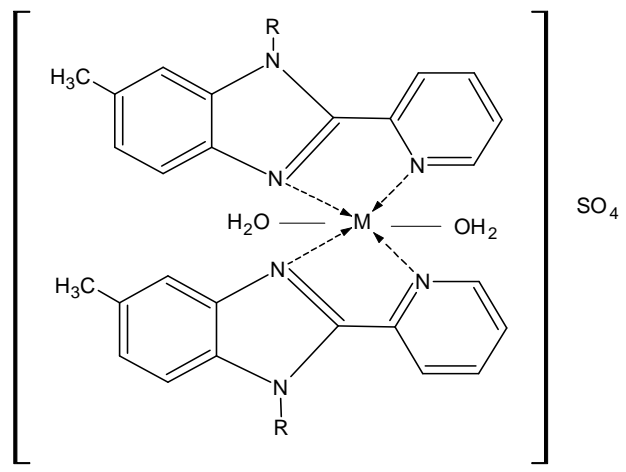

Figure 2. Structure of $\left[\mathrm{ML}_{2}\left(\mathrm{H}_{2} \mathrm{O}\right)_{2}\right] \mathrm{SO}_{4}$ $\left(\mathrm{M}=\mathrm{Fe}^{2+}\right.$ or $\mathrm{Co}^{2+}, \mathrm{R}=n$-Butyl or benzyl $)$ 
Table 1.Analytical results and physical data of complexes

\begin{tabular}{|c|c|c|c|c|}
\hline \multirow{2}{*}{$\begin{array}{l}\text { Compound } \\
L^{\prime}=\text { Btpymbz } \\
L^{\prime \prime}=\text { Bnpymbz }\end{array}$} & \multirow{2}{*}{$\begin{array}{l}\text { Mol. } \\
\text { wt }\end{array}$} & \multicolumn{3}{|c|}{$\%$ Analysis Found (Calculated) } \\
\hline & & $\mathrm{M}$ & $\mathrm{N}$ & $\begin{array}{l}\text { Thiocyanate } \\
\text { /sulphate }\end{array}$ \\
\hline$\left[\mathrm{FeL}_{2}^{\prime}\left(\mathrm{H}_{2} \mathrm{O}\right)_{2}\right] \mathrm{SO}_{4}$ & 718 & $7.64(7.79)$ & $11.46(11.69)$ & $13.45(13.37)$ \\
\hline$\left[\mathrm{CoL}_{2}^{\prime}\left(\mathrm{H}_{2} \mathrm{O}\right)_{2}\right] \mathrm{SO}_{4}$ & 721 & $7.96(8.15)$ & $11.52(11.65)$ & $13.01(13.31)$ \\
\hline$\left[\mathrm{FeL}_{2}^{\prime}(\mathrm{NCS})_{2}\right]$ & 702 & $7.91(7.09)$ & $15.95(15.96)$ & $16.61(16.52)$ \\
\hline$\left[\mathrm{CoL}_{2}^{\prime}(\mathrm{NCS})_{2}\right]$ & 705 & $8.35(8.36)$ & $15.98(16.11)$ & $16.52(16.66)$ \\
\hline$\left[\mathrm{FeL}_{2}^{\prime \prime}\left(\mathrm{H}_{2} \mathrm{O}\right)_{2}\right] \mathrm{SO}_{4}$ & 786 & $6.98(7.12)$ & $10.38(10.69)$ & $11.97(12.18)$ \\
\hline$\left[\mathrm{CoL}_{2}^{\prime \prime}\left(\mathrm{H}_{2} \mathrm{O}\right)_{2}\right] \mathrm{SO}_{4}$ & 789 & $7.32(7.47)$ & $10.42(10.64)$ & $11.87(12.13)$ \\
\hline$\left[\mathrm{FeL}_{2}{ }^{\prime \prime}(\mathrm{NCS})_{2}\right]$ & 770 & $7.18(7.27)$ & $14.38(14.54)$ & $14.88(15.06)$ \\
\hline$\left[\mathrm{CoL}_{2}^{\prime \prime}(\mathrm{NCS})_{2}\right]$ & 773 & $7.51(7.63)$ & $14.32(14.48)$ & $14.70(15.00)$ \\
\hline
\end{tabular}

The results of carbon, hydrogen were determined and results were found in the range of expected for calculated values.

\section{References}

1. Li Y F, Wang G F, He H, Huang W G, Gao F H and Tang W, J Med Chim., 2006, 49, 4790-4794; DOI: 10.1021/jm060330f

2. Baker H A, Symith R D, Wessibach H, Toohey J T, Ladd J N and Volcani B E, J Biological Chem., 1960, 235, 480-488.

3. Mostafa M Ramla, Mohamada A Omer, Tokunda H and Hoda I El-Diwani, Bioorganic Med Chem., 2007, 15, 6489; DOI:10.1016/j.bmc.2007.04.010

4. Carvalho L C R, Marques M M B and Fernandes E, Chem Eur J, 2011, 12, 12544 12555; DOI: $10.1002 /$ chem.201101508

5. Desai G K and Desai R K, Bioorg Med Chem., 2006, 141, 8271-8279; DOI:10.1016/j.bmc.2006.09.017

6. Andrezejewska M, Mullia L Y, Rivera R C, Tapia A, Vilpo L and Kazimierveznk Z, Eur J Med Chem., 2002, 37, 973; DOI:10.1016/S0223-5234(02)01421-6

7. Lever A B P, "Inorganic Electronic Spectroscopy” Ed. Amsterdam Elsevier, 1968, pp 288-375.

8. Nakamoto N, "Infrared and Raman Spectra of Inorganic and Complex Compounds" 1978, John Wiley New York.

9. Das M K, Nath M, Zukerman J J, Inorg Chim Acta, 1983, 71, 49; DOI:10.1016/S0020-1693(00)83637-3 